\title{
Adolescent fiber intake and mammographic breast density in premenopausal women
}

\author{
Lusine Yaghjyan ${ }^{1 *}$, Gabriela L. Ghita ${ }^{2}$, Bernard Rosner ${ }^{3}$, Maryam Farvid ${ }^{4,5}$, Kimberly A. Bertrand ${ }^{6+}$
} and Rulla M. Tamimi ${ }^{3+}$

\begin{abstract}
Background: To date, there is limited and inconsistent epidemiologic evidence for associations of adolescent diet with mammographic breast density, a strong and consistent predictor of breast cancer. We investigated the association of adolescent fiber intake with mammographic density in premenopausal women.

Methods: This study included 743 cancer-free premenopausal women (mean age, 44.9 years) within the Nurses' Health Study II cohort. Percent breast density, absolute dense and non-dense areas were measured from digitized film mammograms using a computer-assisted thresholding technique. Adolescent and adult diet were assessed with a food frequency questionnaire; energy-adjusted nutrient intakes were estimated for each food item. Information regarding breast cancer risk factors was obtained from baseline or biennial questionnaires closest to the mammogram date. We used generalized linear regression to quantify associations between quartiles of adolescent fiber intake and each of the breast density measures, adjusted for potential confounders. Associations were examined separately for total fiber intake; fiber from fruits, vegetables, legumes, and cereal; and food sources of fiber (fruits, vegetables, and nuts).

Results: In multivariable analyses, total fiber intake during adolescence was not associated with percent breast density ( $p$ for trend $=0.64$ ), absolute dense area $(p$ for trend $=0.80$ ), or non-dense area ( $p$ for trend $=0.75$ ). Similarly, neither consumption of fiber from fruits, vegetables, legumes, or cereal nor specific sources of fiber intake (fruits, vegetables, or nuts) during adolescence were associated with any of the mammographic density phenotypes.
\end{abstract}

Conclusions: Our findings do not support the hypothesis that adolescent fiber intake is associated with premenopausal mammographic breast density.

Keywords: Adolescent diet, Breast density, Fiber intake

Abbreviations: BMI, Body Mass Index; Cl, Confidence Interval; FFQ, Food Frequency Questionnaire; HS-FFQ, High School Food Frequency Questionnaire; NHS II, Nurses' Health Study II; RR, Relative Risk

\section{Background}

Mammographic breast density is a well-established and strong predictor of breast cancer risk [1-4]. Appearance of the breast on the mammogram is a reflection of the amount of fat, connective tissue, and epithelial

\footnotetext{
*Correspondence: lyaghjyan@ufl.edu

${ }^{\dagger}$ Equal contributors

${ }^{1}$ Department of Epidemiology, University of Florida, College of Public Health and Health Professions and College of Medicine, 2004 Mowry Rd., Gainesville 32610, FL, USA

Full list of author information is available at the end of the article
}

tissue in the breast [3]. Light (non-radiolucent) areas on the mammogram represent the fibrous and glandular tissues ("mammographically dense"), whereas, the dark (radiolucent) areas are primarily fat. Women with breasts of $75 \%$ or greater percent density (proportion of the total breast area that appears dense on the mammogram) are at four- to sixfold greater risk of breast cancer compared to women with more fat tissues in the breasts $[3,5,6]$. Absolute dense area of the breast that represents fibroglandular tissue has been shown to be positively associated with breast cancer risk in both pre- and postmenopausal 
women [7-13], while non-dense area of the breast (representing adipose tissue) has been inversely associated with breast cancer risk $[7,9,14,15]$.

Some previous studies have suggested that higher fiber intake, particularly during earlier life, may be associated with a reduced risk of breast cancer later in life $[16,17]$. To date, there is limited epidemiologic evidence that diet has a strong influence on mammographic density and inconsistency in results for specific dietary factors [18-24]. An earlier study by Brisson et al. demonstrated an inverse association between adult fiber intake and breast density [25], while a more recent study by Vachon et al. did not find statistically significant associations [22]. Adolescence is a time period of rapid growth and development and emerging evidence suggests that exposures during this time period, including nutrition, may be particularly relevant to breast cancer risk [16, 26-30], which could potentially be reflected in the degree of breast density. However, only a few studies investigated the association between adolescent diet and adult breast density [31-35]. Further, none of these studies comprehensively investigated associations of total fiber intake and fiber from specific sources with breast density. We examined associations of adolescent fiber intake with percent breast density, absolute dense and non-dense areas in premenopausal women using prospective data in healthy women from the Nurses' Health Study II. These associations were examined separately for total fiber intake; fiber from fruits, vegetables, legumes, and cereal; and food sources of fiber (fruits, vegetables, and nuts).

\section{Methods}

\section{Study population and design}

Women included in this study were selected from participants of a breast cancer case-control study nested within the Nurses' Health Study II (NHS II) cohort. This prospective cohort was established in 1989 and followed 116,430 female registered nurses in the United States who were 25-42 years old (NHS II) at enrollment. After administration of the initial questionnaire, information on breast cancer risk factors (body mass index [BMI], reproductive history, and alcohol use) and any diagnoses of cancer or other diseases was updated through biennial questionnaires [3, 36].

A nested case-control approach was originally used as an efficient design to examine the association between selected biomarkers and breast cancer risk within the NHS II cohort [37]. Using incidence density sampling, women who did not have any type of cancer (other than non-melanoma skin cancer) at the time of the case's cancer diagnosis (controls) were matched 1:2 with women diagnosed with in situ or invasive breast cancer (cases) on age at the time of blood collection, menopausal status and postmenopausal hormone use (current versus not current) at blood draw, day/time of blood draw, race/ethnicity and day in the luteal phase [38]. Our analysis included controls from this nested case-control study as well as additional eligible women within this cohort (without a history of any cancer other than non-melanoma skin) who were not included in the original nested breast cancer case-control study. We attempted to obtain mammograms closest to the time of blood collection (or approximately 1997 for those who did not provide blood samples). From all eligible women, 2590 provided consent and had a usable mammogram for density estimation. From the entire cohort only $41 \%$ of women completed a food frequency questionnaire about diet during high school, and of 1874 premenopausal women with available mammograms, only 743 had data on adolescent fiber intake and essential covariates and were included in the analysis. This study was approved by the Institutional Review Board at the Brigham and Women's Hospital. Consent was obtained or implied by return of questionnaires.

\section{Dietary assessment}

Usual dietary intake and alcohol consumption during the past year were assessed with a semi-quantitative food frequency questionnaire (FFQ) with approximately 130 items which was included in the 1991, 1995, 1999, 2003, and 2007 questionnaires [39]. Responses were recorded in nine categories of intake frequency ranging from "never or less than once per month" to "six or more per day" for given portion sizes. Nutrient intakes were calculated by multiplying the frequency of consumption of each item by the nutrient content of the specified portions and then summing across all items, as previously described [39]. Every 4 years, the food composition database was updated to account for changes in the food supply. In 1997, participants were asked if they would be willing to complete a supplemental food frequency questionnaire about diet during high school (HS-FFQ). From the entire cohort, 56,928 women (49\%) indicated willingness to complete the HS-FFQ, and of those 47,355 (83\%) women returned the HS-FFQ in 1998. Food intake during adolescence was measured using a 124-item HSFFQ, which was specifically designed to contain foods that were usually consumed during the periods from 1960 to 1980 when these women would have been in high school. Food items included in the food frequency questionnaire for adolescents and response categories were similar to those in the food frequency questionnaire for adults. Previous studies demonstrated high reproducibility of the nutrient intake estimates from these FFQs [40].

We used energy-adjusted intake estimates in all the analyses. Total fiber intake, fiber from fruit, vegetables, cereal, and legumes were defined as quartiles based on the distribution in the study sample (total fiber: $\leq 17.32$, 17.33-20.40, 20.41-23.37, >23.37 g/day; fiber from fruit: 
$\leq 2.7,2.8-4.2,4.3-5.9,>5.9 \mathrm{~g} /$ day; fiber from vegetables: $\leq 4.4,4.5-6.0,6.1-7.9,>7.9 \mathrm{~g} /$ day; fiber from cereal: $\leq 4.4$, 4.5-5.5, 5.6-6.8, >6.8 g/day; fiber from legumes: $\leq 1.6$, $1.7-2.3,2.4-3.3,>3.3 \mathrm{~g} /$ day). Total nut intake included intake of peanuts and other nuts and categories were $<1$ time/month, 1-3 times/month, 1 time/week, and $\geq 2$ times/week.

\section{Assessment of mammographic breast density}

Mammographic breast density was assessed in three batches approximately 2-3 years apart. To quantify breast density, the craniocaudal views of both breasts for the first two batches of mammograms in the NHS II were digitized at $261 \mu \mathrm{m}$ per pixel with a Lumisys 85 laser film scanner (Lumisys, Sunnyvale, CA, USA). The third batch of NHS II mammograms was digitized using a VIDAR CAD PRO Advantage scanner (VIDAR Systems Corporation; Herndon, VA, USA) and comparable resolution of 150 dots per inch and 12-bit depth). The Cumulus software (University of Toronto, Toronto, ON, Canada) was used for computer-assisted determination of the absolute dense area, non-dense area, and percent mammographic density on all mammograms [3, 41]. All NHS II images were read by a single reader. Although within-batch reproducibility was high (intraclass correlation coefficient $\geq 0.90$ ) [7], density measures varied across the NHS II batches. We included a small subset of identical mammograms in all batches to account for batch drift in density measurement readings. The density measures from the second and third batches of NHS II mammograms were adjusted to account for the batch effect (whether due to intra-reader variability or scanner), as previously described [42]. Additionally, to assess the potential variability in percent density by scanner, we conducted a pilot study of 50 mammograms. These mammograms were scanned using both the Lumysis 85 laser scanner and the VIDAR CAD PRO Advantage scanner; percent density was measured by the same observer using Cumulus. The correlation between percent density as measured by the two scanners was 0.88 .

Percent breast density was measured as percentage of the total area occupied by epithelial/stromal tissue (absolute dense area) divided by the total breast area. Because breast densities of the right and left breast for an individual woman are strongly correlated [41], the average density of both breasts was used in this analysis.

\section{Covariate information}

Information on breast cancer risk factors was obtained from the biennial questionnaires closest to the date of the mammogram. For exclusion from this analysis, women were considered to be postmenopausal if they reported:
(1) no menstrual periods within the 12 months before blood collection with natural menopause, (2) bilateral oophorectomy, or (3) hysterectomy with one or both ovaries retained, and were 54 years or older for ever smokers or 56 years or older for never smokers [43, 44].

\section{Statistical analysis}

We used generalized linear regression to examine the associations of total fiber intake; fiber from fruits, vegetables, legumes, and cereal; and food sources of fiber (fruits, vegetables, and nuts) with percent density, absolute dense and non-dense areas, while taking into account the correlation between matched controls [45]. Because absolute dense and non-dense area measures were non-normally distributed, we used square root transformation to improve normality in all the regression analyses. Percent breast density did not require transformation. The lowest fiber intake category was used as the reference. The regression estimates were adjusted for age (continuous), body mass index (continuous), body mass index at age 18 (continuous), age at menarche $(<12,12-13,>13$ years), parity and age at first child's birth (nulliparous, 1-4 children with age at first birth $<25$ years, $1-4$ children with age at first birth of 25-29 years, 1-4 children with age at first birth of $\geq 30$ years, $\geq 5$ children with age at first birth of $<25$ years, or $\geq 5$ children with age at first birth of $\geq 25$ years), a confirmed history of benign breast disease (yes, no), a family history of breast cancer (yes, no), alcohol consumption $(0,0-<5, \geq 5$ g/day, unknown), average consumption of the same nutrient in adulthood (quartiles), caloric intake in adolescence (continuous), and average caloric intake in adulthood (continuous). Average nutrient and caloric intake in adulthood were calculated as the average of the estimates from all available FFQs administered before the date of the mammogram. In a secondary analysis, the regression estimates for nuts were additionally adjusted for adolescent total fiber intake. Finally, we calculated the mean intake of total fiber and nuts from the adolescent and adult intake estimates and explored the association of these average intake estimates with breast density measures in a sensitivity analysis.

To assess the overall trend for each of the types of the fiber intake, we used respective medians within each category. For nut consumption, the intake frequencies were first converted into servings and then the median servings in each quartile were used in the trend analysis. Statistical significance in all the analyses was assessed at 0.05 level. The analyses were performed using SAS software (version 9.2, SAS Institute, Cary, NC, USA).

\section{Results}

In this study of 743 cancer-free premenopausal women, the average age at the mammogram was 44.9 years (range 34.0-55.0). Women in the highest total fiber intake quartile had a mean percent density of $41.2 \%$, mean absolute dense 
area of $94.4 \mathrm{~cm}^{2}$, and mean non-dense area of $146.2 \mathrm{~cm}^{2}$ as compared to $40.8 \%, 90.9 \mathrm{~cm}^{2}$, and $144.7 \mathrm{~cm}^{2}$ in women from the lowest quartile, respectively. Distributions of breast cancer risk factors by the quartiles of total fiber intake are presented in Table 1. Women in the highest quartile of adolescent total fiber intake as compared to the lowest quartile had higher adult caloric and total fiber intake (1894 vs. 1732 calories and 21.6 vs. $17.1 \mathrm{~g} /$ day, respectively). There was a greater proportion of nulliparous women and women with a positive family history of breast cancer in the highest quartile of adolescent fiber intake as compared to the lowest quartile. Distribution of other risk factors did not differ by the adolescent total fiber intake.

In multivariable analyses, total fiber intake during adolescence was not associated with percent breast density ( $p$ trend $=0.64)$, absolute dense area $(p$ trend $=0.80)$, or non-dense area ( $p$ trend $=0.75$ ) (Table 2 ). We found a marginal association of adolescent nut intake with absolute non-dense breast area only ( $p$ for trend $=0.05$ ); however, this association was lacking a clear pattern ( $\beta=0.06,0.62$ and 0.35 for $1-3$ times/month, 1 time/week, and $\geq 2$ times/week, respectively). The results were similar with additional adjustment for adolescent total fiber intake. Neither specific types of fiber nor major sources of fiber intake (fruits, vegetables, legumes, or cereal) during adolescence were associated with any of the mammographic density phenotypes (Table 2). Finally, we explored the association of the average consumption of total fiber and nuts between adolescence and adulthood with breast density; we found no statistically significant associations (data not shown).

\section{Discussion}

In this study of cancer-free premenopausal women, we investigated the associations of adolescent fiber intake with mammographic density, a strong and consistent

Table 1 Descriptive characteristics of the study population $(n=743)$, by quartile of adolescent total fiber intake

\begin{tabular}{|c|c|c|c|c|}
\hline \multirow[t]{3}{*}{ Characteristic } & \multicolumn{4}{|c|}{ Adolescent total fiber intake quartile } \\
\hline & \multirow{2}{*}{$\begin{array}{l}1^{\text {st }} \\
(\leq 17.32 \mathrm{~g} / \text { day, } \\
\text { median } 15.7) \mathrm{n}=183\end{array}$} & \multirow{2}{*}{$\begin{array}{l}2^{\text {nd }} \\
(17.33-20.40 \mathrm{~g} / \text { day, } \\
\text { median } 18.9) \mathrm{n}=184\end{array}$} & \multirow{2}{*}{$\begin{array}{l}3^{\text {rd }} \\
(20.41-23.37 \mathrm{~g} / \text { day, } \\
\text { median 21.6) } \mathrm{n}=190\end{array}$} & \multirow{2}{*}{$\begin{array}{l}4^{\text {th }} \\
(>23.37 \mathrm{~g} / \text { day, } \\
\text { median } 26.5) \mathrm{n}=186\end{array}$} \\
\hline & & & & \\
\hline \multicolumn{5}{|l|}{ Mean (STD) } \\
\hline Age at mammogram, years & $45.2(4.2)$ & $44.9(4.0)$ & $45.0(4.1)$ & $44.6(4.0)$ \\
\hline BMI at mammogram & $25.9(6.0)$ & $25.2(5.6)$ & $25.2(4.7)$ & $25.6(6.5)$ \\
\hline $\mathrm{BMI}$ at age 18 & $21.1(3.0)$ & $20.9(2.7)$ & $20.9(2.8)$ & $21.3(3.3)$ \\
\hline Percent density & $40.8(18.3)$ & $41.5(17.5)$ & $41.2(18.6)$ & $41.2(18.0)$ \\
\hline Absolute dense area, $\mathrm{cm}^{2}$ & $90.9(48.0)$ & $94.3(50.0)$ & $96.3(52.0)$ & $94.4(50.3)$ \\
\hline Non-dense area, $\mathrm{cm}^{2}$ & $144.7(78.4)$ & $141.9(76.8)$ & $147.5(78.2)$ & $146.2(79.2)$ \\
\hline Age at menarche, years & $12.4(1.4)$ & $12.3(1.4)$ & $12.4(1.5)$ & $12.4(1.6)$ \\
\hline Caloric intake, adolescence & $2730(848)$ & 2672(702) & $2857(773)$ & $2800(768)$ \\
\hline Caloric intake, adult $^{\mathrm{a}}$ & $1732(453)$ & $1820(445)$ & $1858(467)$ & $1894(531)$ \\
\hline Alcohol consumption, g/day & $4.1(6.0)$ & $4.6(8.7)$ & $4.8(8.5)$ & $4.6(7.3)$ \\
\hline Adult total fiber intake, median (range) ${ }^{\mathrm{b}}$ & $17.1(8.1-35.3)$ & $18.0(5.9-39.5)$ & $19.2(8.4-48.4)$ & $21.6(12.3-43.6)$ \\
\hline \multicolumn{5}{|l|}{ Number (\%) } \\
\hline \multicolumn{5}{|l|}{ Parity/age at first child's birth } \\
\hline Nulliparous & $31(16.9)$ & $34(18.5)$ & $34(17.9)$ & $47(25.3)$ \\
\hline $1-4$ children, $<25$ years & $57(31.2)$ & $54(29.4)$ & $50(26.3)$ & $42(22.6)$ \\
\hline 1-4 children, $25-29$ years & $60(32.8)$ & $66(35.9)$ & $64(33.7)$ & $63(33.9)$ \\
\hline $1-4$ children, $\geq 30$ years & $34(18.6)$ & $28(15.2)$ & $40(21.1)$ & $32(17.2)$ \\
\hline$\geq 5$ children, $<25$ years & $1(0.6)$ & $1(0.5)$ & $2(1.1)$ & $2(1.1)$ \\
\hline$\geq 5$ children, $\geq 25$ years & 0 & $1(0.5)$ & 0 & 0 \\
\hline History of biopsy-confirmed benign breast disease & $34(18.6)$ & $37(20.1)$ & $33(17.4)$ & $32(17.2)$ \\
\hline Family history of breast cancer & $13(7.1)$ & $16(8.7)$ & $17(9.0)$ & 19 (10.2) \\
\hline
\end{tabular}

Abbreviations: BMI body mass index, STD standard deviation

${ }^{a}$ Difference across adolescent total fiber intake quartiles statistically significant at 0.01 level (analysis of variance for continuous variables or chi-square test for categorical variables)

${ }^{b}$ Difference across adolescent total fiber intake quartiles statistically significant at 0.001 level (analysis of variance for continuous variables or chi-square test for categorical variables) 
Table 2 Association of adolescent fiber intake with premenopausal breast density (coefficient and $95 \%$ confidence interval) $(n=743$ )

\begin{tabular}{|c|c|c|c|c|c|c|c|}
\hline \multirow[t]{2}{*}{ Type of fiber/food group } & \multicolumn{3}{|c|}{$\begin{array}{l}\text { Percent density } \\
\text { (untransformed) }\end{array}$} & \multicolumn{2}{|c|}{$\begin{array}{l}\text { Absolute dense area } \\
\text { (square root- transformed) }\end{array}$} & \multicolumn{2}{|c|}{$\begin{array}{l}\text { Non-dense area } \\
\text { (square root-transformed) }\end{array}$} \\
\hline & $\mathrm{N}$ & Age/BMl adjusted & Fully adjusted $^{a}$ & Age/BMl adjusted & Fully adjusted $^{a}$ & Age/BMl adjusted & Fully adjusted $^{a}$ \\
\hline \multicolumn{8}{|c|}{ Total fiber, quartile (quartile median) } \\
\hline $1^{\text {st }}(15.7)$ & 183 & Reference & Reference & Reference & Reference & Reference & Reference \\
\hline $2^{\text {nd }}(18.9)$ & 184 & $-0.51(-3.62,2.60)$ & $-0.66(-3.62,2.31)$ & $0.13(-0.38,0.63)$ & $0.00(-0.50,0.49)$ & $0.16(-0.34,0.65)$ & $0.09(-0.40,0.57)$ \\
\hline $3^{\text {rd }}(21.6)$ & 190 & $-0.74(-3.83,2.35)$ & $-1.04(-4.30,2.22)$ & $0.22(-0.28,0.72)$ & $0.10(-0.42,0.61)$ & $0.36(-0.13,0.85)$ & $0.34(-0.17,0.85)$ \\
\hline $4^{\text {th }}(26.5)$ & 186 & $-0.19(-3.29,2.92)$ & $-0.82(-4.16,2.53)$ & $0.14(-0.37,0.64)$ & $-0.09(-0.61,0.44)$ & $0.16(-0.33,0.66)$ & $0.06(-0.49,0.61)$ \\
\hline$p$ trend & & 0.92 & 0.64 & 0.59 & 0.80 & 0.48 & 0.75 \\
\hline
\end{tabular}

Fiber from fruits, quartile (quartile median)

\begin{tabular}{|c|c|c|c|c|c|c|c|}
\hline $1^{\text {st }}(1.9)$ & 193 & Reference & Reference & Reference & Reference & Reference & Reference \\
\hline $2^{\text {nd }}(3.5)$ & 184 & $-0.10(-3.18,2.97)$ & $-0.71(-3.73,2.31)$ & $0.00(-0.49,0.50)$ & $-0.01(-0.54,0.53)$ & $0.07(-0.42,0.56)$ & $0.23(-0.27,0.73)$ \\
\hline $3^{\text {rd }}(5.0)$ & 184 & $-0.65(-3.72,2.42)$ & $-2.11(-5.28,1.05)$ & $-0.18(-0.68,0.31)$ & $-0.30(-0.80,0.20)$ & $0.01(-0.48,0.50)$ & $0.21(-0.30,0.73)$ \\
\hline $4^{\text {th }}(7.2)$ & 182 & $-0.01(-3.09,3.07)$ & $-1.96(-5.29,1.38)$ & $0.03(-0.47,0.53)$ & $-0.26(-0.80,0.29)$ & $0.11(-0.38,0.60)$ & $0.29(-0.28,0.86)$ \\
\hline$p$ trend & & 0.94 & 0.21 & 0.95 & 0.24 & 0.72 & 0.36 \\
\hline
\end{tabular}

Fiber from vegetables, quartile (quartile median)

\begin{tabular}{|c|c|c|c|c|c|c|c|}
\hline $1^{\text {st }}(3.4)$ & 187 & Reference & Reference & Reference & Reference & Reference & Reference \\
\hline $2^{\text {nd }}(5.2)$ & 190 & $-0.33(-3.40,2.74)$ & $-0.15(-3.17,2.86)$ & $0.20(-0.29,0.70)$ & $0.22(-0.27,0.70)$ & $0.18(-0.31,0.67)$ & $0.11(-0.37,0.58)$ \\
\hline $3^{\text {rd }}(6.8)$ & 180 & $-0.59(-3.70,2.52)$ & $0.64(-2.40,3.69)$ & $0.23(-0.28,0.73)$ & $0.36(-0.16,0.87)$ & $0.36(-0.14,0.85)$ & $0.19(-0.30,0.68)$ \\
\hline $4^{\text {th }}(9.8)$ & 186 & $0.36(-2.72,3.44)$ & $1.05(-2.21,4.32)$ & $0.25(-0.25,0.75)$ & $0.29(-0.24,0.82)$ & $0.15(-0.34,0.64)$ & $-0.02(-0.56,0.53)$ \\
\hline$p$ trend & & 0.80 & 0.46 & 0.37 & 0.31 & 0.54 & 0.91 \\
\hline
\end{tabular}

Fiber from legumes, quartile (quartile median)

\begin{tabular}{|c|c|c|c|c|c|c|c|}
\hline $1^{\text {st }}(1.2)$ & 201 & Reference & Reference & Reference & Reference & Reference & Reference \\
\hline $2^{\text {nd }}(2.0)$ & 186 & $-2.75(-5.58,0.09)$ & $-2.92(-5.72,-0.12)$ & $-0.13(-0.61,0.36)$ & $-0.14(-0.61,0.34)$ & $0.29(-0.18,0.77)$ & $0.34(-0.13,0.81)$ \\
\hline $3^{\text {rd }}(2.7)$ & 177 & $0.40(-2.73,3.53)$ & $-0.31(-3.55,2.93)$ & $0.15(-0.34,0.65)$ & $0.10(-0.41,0.60)$ & $0.01(-0.50,0.53)$ & $0.14(-0.40,0.68)$ \\
\hline $4^{\text {th }}(4.5)$ & 179 & $-0.02(-3.02,2.97)$ & $0.20(-2.94,3.34)$ & $0.16(-0.33,0.65)$ & $0.17(-0.34,0.68)$ & $0.09(-0.39,0.57)$ & $0.04(-0.46,0.54)$ \\
\hline$p$ trend & & 0.56 & 0.49 & 0.37 & 0.38 & 0.97 & 0.83 \\
\hline
\end{tabular}

Fiber from cereal quartile (quartile median)

\begin{tabular}{|c|c|c|c|c|c|c|c|}
\hline $1^{\text {st }}(3.8)$ & 194 & Reference & Reference & Reference & Reference & Reference & Reference \\
\hline $2^{\text {nd }}(5.0)$ & 173 & $-0.14(-3.18,2.90)$ & $-0.90(-3.92,2.12)$ & $-0.10(-0.60,0.40)$ & $-0.23(-0.74,0.27)$ & $-0.11(-0.59,0.37)$ & $-0.04(-0.52,0.44)$ \\
\hline $3^{\text {rd }}(6.1)$ & 203 & $0.67(-2.31,3.65)$ & $0.48(-2.51,3.47)$ & $0.10(-0.38,0.59)$ & $0.08(-0.41,0.57)$ & $-0.12(-0.61,0.37)$ & $-0.08(-0.58,0.42)$ \\
\hline $4^{\text {th }}(7.9)$ & 173 & $-1.02(-4.00,1.97)$ & $-1.84(-4.86,1.18)$ & $-0.20(-0.71,0.30)$ & $-0.29(-0.80,0.23)$ & $-0.04(-0.53,0.45)$ & $0.06(-0.45,0.57)$ \\
\hline$p$ trend & & 0.61 & 0.36 & 0.57 & 0.47 & 0.89 & 0.83 \\
\hline
\end{tabular}

Total nuts, servings

\begin{tabular}{|c|c|c|}
\hline \multirow[t]{2}{*}{ pe of fiber/food group } & \multicolumn{2}{|c|}{$\begin{array}{l}\text { Percent density } \\
\text { (untransformed) }\end{array}$} \\
\hline & $\mathrm{N}$ & Age/BMl adjusted \\
\hline \multicolumn{3}{|c|}{ tal fiber, quartile (quartile median) } \\
\hline$(15.7)$ & 183 & Reference \\
\hline d $(18.9)$ & 184 & $-0.51(-3.62,2.60)$ \\
\hline$d(21.6)$ & 190 & $-0.74(-3.83,2.35)$ \\
\hline$(26.5)$ & 186 & $-0.19(-3.29,2.92)$ \\
\hline rend & & 0.92 \\
\hline \multicolumn{3}{|c|}{ er from fruits, quartile (quartile median) } \\
\hline st (1.9) & 193 & Reference \\
\hline (3.5) & 184 & $-0.10(-3.18,2.97)$ \\
\hline$(5.0)$ & 184 & $-0.65(-3.72,2.42)$ \\
\hline$(7.2)$ & 182 & $-0.01(-3.09,3.07)$ \\
\hline end & & 0.94 \\
\hline \multicolumn{3}{|c|}{ er from vegetables, quartile (quartile median) } \\
\hline (3.4) & 187 & Reference \\
\hline$(5.2)$ & 190 & $-0.33(-3.40,2.74)$ \\
\hline (6.8) & 180 & $-0.59(-3.70,2.52)$ \\
\hline$(9.8)$ & 186 & $0.36(-2.72,3.44)$ \\
\hline rend & & 0.80 \\
\hline \multicolumn{3}{|c|}{ er from legumes, quartile (quartile median) } \\
\hline$(1.2)$ & 201 & Reference \\
\hline d $(2.0)$ & 186 & $-2.75(-5.58,0.09)$ \\
\hline$(2.7)$ & 177 & $0.40(-2.73,3.53)$ \\
\hline$(4.5)$ & 179 & $-0.02(-3.02,2.97)$ \\
\hline rend & & 0.56 \\
\hline \multicolumn{3}{|c|}{ er from cereal quartile (quartile median) } \\
\hline st $(3.8)$ & 194 & Reference \\
\hline nd $(5.0)$ & 173 & $-0.14(-3.18,2.90)$ \\
\hline rd $(6.1)$ & 203 & $0.67(-2.31,3.65)$ \\
\hline th $(7.9)$ & 173 & $-1.02(-4.00,1.97)$ \\
\hline end & & 0.61 \\
\hline & & \\
\hline month (0 serv/day) & 307 & Reference \\
\hline
\end{tabular}

Reference Reference Reference

1-3/month (0.07 serv/day) $177 \quad-1.00(-3.81,1.81) \quad-1.11(-4.00,1.77) \quad-0.18(-0.64,0.27) \quad-0.17(-0.62,0.29) \quad 0.05(-0.40,0.50)$

$0.06(-0.38,0.50)$

$1 /$ week $(0.14$ serv/day) $\quad 233-1.07(-3.66,1.52) \quad-1.79(-4.52,0.94) \quad 0.14(-0.28,0.56)$

$0.11(-0.34,0.57) \quad 0.49(0.08,0.90)$

$0.62(0.17,1.07)$

$\geq 2 /$ week $(0.57$ serv/day $) \quad 24 \quad-1.54(-7.89,4.81) \quad-2.49(-8.70,3.71) \quad 0.03(-1.00,1.06)$

$p$ trend

$0.48 \quad 0.27$

0.72

$-0.06(-1.20,1.08) \quad 0.23(-0.78,1.23)$

$0.35(-0.37,1.07)$

Fruit intake, quartile (quartile median)

\begin{tabular}{|c|c|c|c|c|c|c|c|}
\hline $1^{\text {st }}(0.6)$ & 188 & Reference & Reference & Reference & Reference & Reference & Reference \\
\hline $2^{\text {nd }}(1.2)$ & 183 & $-0.39(-3.29,2.51)$ & $-0.43(-3.47,2.61)$ & $0.08(-0.40,0.56)$ & $0.17(-0.34,0.68)$ & $0.25(-0.21,0.71)$ & $0.36(-0.13,0.84)$ \\
\hline $3^{\text {rd }}(1.8)$ & 181 & $0.34(-2.70,3.38)$ & $-0.30(-3.66,3.06)$ & $0.13(-0.34,0.61)$ & $0.19(-0.35,0.73)$ & $0.15(-0.34,0.64)$ & $0.38(-0.15,0.91)$ \\
\hline $4^{\text {th }}(2.7)$ & 191 & $-0.18(-3.18,2.82)$ & $-1.32(-4.89,2.26)$ & $0.15(-0.36,0.66)$ & $0.07(-0.55,0.68)$ & $0.27(-0.21,0.75)$ & $0.48(-0.09,1.06)$ \\
\hline$p$ trend & & $>0.99$ & 0.75 & 0.55 & 0.88 & 0.36 & 0.14 \\
\hline
\end{tabular}


Table 2 Association of adolescent fiber intake with premenopausal breast density (coefficient and $95 \%$ confidence interval) $(n=743$ ) (Continued)

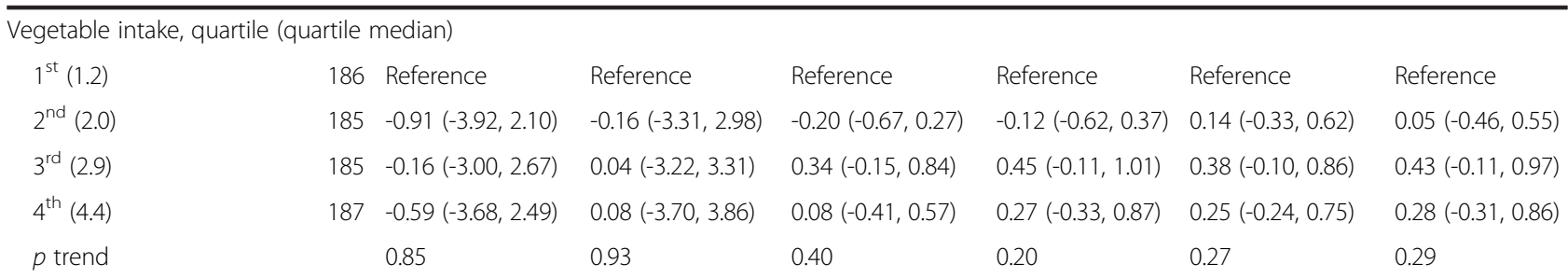

Abbreviations: $B M I$ body mass index

${ }^{a}$ Adjusted for age (continuous), body mass index (continuous), body mass index at age 18 (continuous), age at menarche $(<12,12-13,>13$ years), parity and age at first child's birth (nulliparous, 1-4 children with age at first birth $<25$ years, 1-4 children with age at first birth of 25-29 years, 1-4 children with age at first birth of $\geq 30$ years, $\geq 5$ children with age at first birth of $<25$ years, or $\geq 5$ children with age at first birth of $\geq 25$ years), a confirmed history of benign breast disease (yes, no), a family history of breast cancer (yes, no), alcohol consumption $(0,0-<5, \geq 5 \mathrm{~g} /$ day, unknown), average consumption of the same nutrient in adulthood (quartiles), caloric intake in adolescence (continuous), average caloric intake in adulthood (continuous)

predictor of breast cancer. Adolescent fiber intake was not associated with any of breast density phenotypes. While we noted a borderline significant positive association between total nut intake during adolescence and absolute non-dense breast area, the lack of clear pattern of association suggests that this could be a chance finding. Our findings contribute to the very limited evidence on the association of adolescent fiber intake and premenopausal breast density.

Some, but not all, previous studies have suggested that higher fiber intake may be associated with a reduced risk of breast cancer [46, 47]. A recent meta-analysis of prospective studies found an inverse association of total fiber with breast cancer risk (relative risk [RR] for high vs. low intake $=0.93,95 \%$ confidence interval [CI] 0.89-0.98 for total fiber), though the magnitude of this association was only modest [47]. Adolescent fiber intake has been suggested to reduce breast cancer risk in adulthood in some of the previous studies $[16,27,48]$. The results of an earlier study in NHS showed reduced risk of breast cancer in women with higher adolescent dietary fiber intake ( RR for $5^{\text {th }}$ quantile vs. $1^{\text {st }}$ quantile $=0.78, p$ trend $=0.09$ ) [27]. A recent analysis in the NHS II also showed a significant inverse association between adolescent fiber intake and breast cancer ( $R R=0.81$ for highest vs. lowest quintile; $95 \%$ CI $0.72-0.91 ; p$ trend $=0.002$ ) [17]. In the NHS II, high fiber and nut intake during adolescence was also associated with significantly lower risk of benign breast disease, another strong breast cancer risk factor (hazard ratio [HR] for highest vs. lowest quintile of adolescent fiber intake $=0.75,95 \%$ CI 0.59-0.96) [49].

Several biological mechanisms were suggested as a possible explanation for potential effects of dietary fiber on breast cancer risk, including its influence on circulating estrogen levels via inhibited intestinal reabsorption and increased fecal excretion as well as increased small intestine transit time leading to a slower glucose absorption and reduced insulin secretion [47]. On the other hand, a recent study reported a positive association between fiber intake and insulin-like growth factor 1 (IGF-I) concentrations (1.9\% increase per each standard deviation increase in intake) [50], which previously showed positive association with breast cancer risk [51] and mammographic breast density $[52,53]$.

Very limited data exists on associations of adolescent or childhood fiber intake and breast density. Among 1161 cancer-free women participating in a British cohort (Medical Research Council National Survey of Health and Development), there was no statistically significant association between low-fat/high-fiber dietary pattern at age 4 years and adult percent density evaluated with computer-assisted thresholding method [32]. A follow-up study among 230 participants in the Dietary Intervention Study in Children found no statistically significant associations of fiber intake at age 8-10 years with fibroglandular volume, measured with non-contrast MRI or the ratio of the fibroglandular volume over total volume of the breast at ages 25-29 [31]. Similarly, we found no statistically significant association of adolescent total fiber intake or fiber from specific sources and food groups with breast density.

Our study is the largest study to date that systematically investigated associations of adolescent fiber intake with mammographic breast density in premenopausal women. We examined, for the first time, the associations of adolescent fiber intake with absolute dense and nondense area. In addition to the total fiber intake, we examined associations of specific sources of fiber and food groups with breast density. The analysis used data from the Nurses' Health Study II, an established cohort with more than 25 years of follow-up, ascertainment of disease status, and comprehensive information on breast cancer risk factors and breast density. While we found no statistically significant associations, with $n=743$, we had sufficient statistical power $(>80 \%)$ to detect even modest effects (e.g., 5-10 percentage points in average percent mammographic density, which translates into approximately $7 \%$ change in breast cancer risk $[6,54]$ ) thus making our null result informative. 
Our study has a few limitations. The examined associations are based on the density measures from a single mammogram, which might not be reflective of the woman's lifelong density pattern; however, studies have suggested that a single measure can predict breast cancer risk for up to 10 years in both pre- and postmenopausal women $[6,55]$. Despite the prospective nature of the cohort, potential errors in recall of fiber intake, especially for adolescent diet, are possible, since women recalled their high school diet (on average 20-23 years from before the questionnaire date). However, previous studies suggest that recall of adolescent diet is reasonably reproducible and sufficiently precise to examine associations of adolescent diet with health outcomes in epidemiologic studies [56].

\section{Conclusions}

We investigated the associations of adolescent fiber intake with percent density, absolute dense and non-dense areas in premenopausal women. Our findings do not support the hypothesis that adolescent fiber intake is associated with premenopausal mammographic density. If observed associations with breast cancer risk are causal, then the effect may not be mediated through mammographic density.

\section{Acknowledgements}

This work was supported by the National Cancer Institute at the National Institutes of Health [CA131332, CA087969, CA175080 to RMT, UM1 CA186107 to MS, UM1 CA176726 to WW], Avon Foundation for Women, Susan G. Komen for the Cure ${ }^{\circledast}$, and Breast Cancer Research Foundation. KAB is supported in part by the Simeon J. Fortin Charitable Foundation, Bank of America, NA, Co-Trustee.

\section{Availability of supporting data}

Not applicable.

\section{Authors' contributions}

$L Y$ and $K A B$ conceived of and designed the study, directed statistical analyses, interpreted results, substantially revised initial drafts of the manuscript and provided final review and approval. RMT led all aspects pertaining to data acquisition. LY, RMT, KAB, and BR performed statistical analyses and interpretation of data. LY wrote the first draft of the manuscript, which was critically revised by $K A B$, with contribution from GLG, BR, and MF. All authors read and approved the final manuscript. LY and KAB supervised the overall study progress.

\section{Authors' information}

No further information.

\section{Competing interests}

The authors declare that they have no competing interests.

\section{Consent for publication}

Not applicable.

\section{Ethical approval and consent to participate}

This study was approved by the Institutional Review Board at the Brigham and Women's Hospital. Consent was obtained or implied by return of questionnaires.

\section{Author details}

'Department of Epidemiology, University of Florida, College of Public Health and Health Professions and College of Medicine, 2004 Mowry Rd., Gainesville 32610, FL, USA. ${ }^{2}$ Department of Biostatistics, University of Florida, College of
Public Health and Health Professions and College of Medicine, Gainesville, FL, USA. ${ }^{3}$ Channing Division of Network Medicine, Department of Medicine, Brigham and Women's Hospital and Harvard Medical School, Boston, MA, USA. ${ }^{4}$ Department of Nutrition, Harvard T.H. Chan School of Public Health, Boston, MA, USA. ${ }^{5}$ Harvard/Massachusetts General Hospital Center on Genomics, Vulnerable Populations, and Health Disparities, Mongan Institute for Health Policy, Massachusetts General Hospital, Boston, MA, USA. 'Slone Epidemiology Center at Boston University, Boston, MA, USA.

Received: 28 March 2016 Accepted: 29 July 2016

Published online: 12 August 2016

\section{References}

1. Boyd NF, Rommens JM, Vogt K, Lee V, Hopper JL, Yaffe MJ, Paterson AD. Mammographic breast density as an intermediate phenotype for breast cancer. Lancet Oncol. 2005;6(10):798-808.

2. Ginsburg OM, Martin LJ, Boyd NF. Mammographic density, lobular involution, and risk of breast cancer. Br J Cancer. 2008;99(9):1369-74.

3. Tamimi RM, Byrne C, Colditz GA, Hankinson SE. Endogenous hormone levels, mammographic density, and subsequent risk of breast cancer in postmenopausal women. J Natl Cancer Inst. 2007;99(15):1178-87.

4. Harvey JA, Bovbjerg VE. Quantitative assessment of mammographic breast density: relationship with breast cancer risk. Radiology. 2004;230(1):29-41.

5. Boyd NF, Byng JW, Jong RA, Fishell EK, Little LE, Miller AB, Lockwood GA, Tritchler DL, Yaffe MJ. Quantitative classification of mammographic densities and breast cancer risk: results from the Canadian National Breast Screening Study. J Natl Cancer Inst. 1995;87(9):670-5.

6. Byrne C, Schairer C, Wolfe J, Parekh N, Salane M, Brinton LA, Hoover R, Haile R. Mammographic features and breast cancer risk: effects with time, age, and menopause status. J Natl Cancer Inst. 1995;87(21):1622-9.

7. Pettersson A, Hankinson S, Willett W, Lagiou P, Trichopoulos D, Tamimi R. Nondense mammographic area and risk of breast cancer. Breast Cancer Res. 2011;13(5):R100

8. Aitken Z, McCormack VA, Highnam RP, Martin L, Gunasekara A, Melnichouk O, Mawdsley G, Peressotti C, Yaffe M, Boyd NF, et al. Screen-film mammographic density and breast cancer risk: a comparison of the volumetric standard mammogram form and the interactive threshold measurement methods. Cancer Epidemiol Biomark Prev. 2010;19(2):418-28.

9. Stone J, Ding J, Warren RM, Duffy SW, Hopper JL. Using mammographic density to predict breast cancer risk: dense area or percentage dense area. Breast Cancer Res. 2010;12(6):R97.

10. Ursin G, Ma H, Wu AH, Bernstein L, Salane M, Parisky YR, Astrahan M, Siozon CC, Pike MC. Mammographic density and breast cancer in three ethnic groups. Cancer Epidemiol Biomark Prev. 2003;12(4):332-8.

11. Maskarinec G, Pagano I, Lurie G, Wilkens LR, Kolonel LN. Mammographic density and breast cancer risk. Am J Epidemiol. 2005;162(8):743-52.

12. Boyd N, Martin L, Gunasekara A, Melnichouk O, Maudsley G, Peressotti C, Yaffe M, Minkin S. Mammographic density and breast cancer risk: evaluation of a novel method of measuring breast tissue volumes. Cancer Epidemiol Biomark Prev. 2009;18(6):1754-62.

13. Vachon CM, Brandt KR, Ghosh K, Scott CG, Maloney SD, Carston MJ, Pankratz VS, Sellers TA. Mammographic breast density as a general marker of breast cancer risk. Cancer Epidemiol Biomark Prev. 2007;16(1):43-9.

14. Lokate M, Peeters PH, Peelen LM, Haars G, Veldhuis WB, van Gils CH. Mammographic density and breast cancer risk: the role of the fat surrounding the fibroglandular tissue. Breast Cancer Res. 2011;13(5):R103.

15. Pettersson A, Graff RE, Ursin G, Santos Silva ID, McCormack V, Baglietto L, Vachon C, Bakker MF, Giles GG, Chia KS, et al. Mammographic density phenotypes and risk of breast cancer: a meta-analysis. J Natl Cancer Inst. 2014;106(5):dju078. doi:10.1093/jnci/dju078.

16. Mahabir S. Association between diet during preadolescence and adolescence and risk for breast cancer during adulthood. J Adolesc Health. 2013;52(5 Suppl):S30-35.

17. Farvid M, Eliassen A, Cho E, Liao X, Chen W, Willett W. Dietary fiber intake in young adults and breast cancer risk. Pediatrics. 2016;137(3), e20151226.

18. Boyd NF, Greenberg C, Lockwood G, Little L, Martin L, Byng J, Yaffe M, Tritchler D. Effects at two years of a low-fat, high-carbohydrate diet on radiologic features of the breast: results from a randomized trial. Canadian Diet and Breast Cancer Prevention Study Group. J Natl Cancer Inst. 1997;89(7):488-96 
19. Martin LJ, Greenberg CV, Kriukov V, Minkin S, Jenkins DJ, Yaffe M, Hislop G, Boyd NF. Effect of a low-fat, high-carbohydrate dietary intervention on change in mammographic density over menopause. Breast Cancer Res Treat. 2009;113(1):163-72.

20. Masala G, Ambrogetti D, Assedi M, Giorgi D, Del Turco MR, Palli D. Dietary and lifestyle determinants of mammographic breast density. A longitudinal study in a Mediterranean population. Int J Cancer. 2006;118(7):1782-9.

21. Sala E, Warren R, Duffy S, Welch A, Luben R, Day N. High risk mammographic parenchymal patterns and diet: a case-control study. Br J Cancer. 2000;83(1):121-6.

22. Vachon CM, Kushi LH, Cerhan JR, Kuni CC, Sellers TA. Association of diet and mammographic breast density in the Minnesota breast cancer family cohort. Cancer Epidemiol Biomarkers Prev. 2000;9(2):151-60.

23. Tseng M, Vierkant RA, Kushi LH, Sellers TA, Vachon CM. Dietary patterns and breast density in the Minnesota Breast Cancer Family Study. Cancer Causes Control. 2008;19(5):481-9.

24. Takata Y, Maskarinec G, Park SY, Murphy SP, Wilkens LR, Kolonel LN Mammographic density and dietary patterns: the multiethnic cohort. Eur J Cancer Prev. 2007;16(5):409-14.

25. Brisson J, Verreault R, Morrison AS, Tennina S, Meyer F. Diet, mammographic features of breast tissue, and breast cancer risk. Am J Epidemiol. 1989;130(1):14-24.

26. Berkey CS, Frazier AL, Gardner JD, Colditz GA. Adolescence and breast carcinoma risk. Cancer. 1999;85(11):2400-9.

27. Frazier AL, Ryan $C T$, Rockett $H$, Willett WC, Colditz GA. Adolescent diet and risk of breast cancer. Breast Cancer Res. 2003;5(3):R59-64.

28. Zhao Y, Tan YS, Aupperlee MD, Langohr IM, Kirk EL, Troester MA, Schwartz RC, Haslam SZ. Pubertal high fat diet: effects on mammary cancer development. Breast cancer research : BCR. 2013;15(5):R100.

29. Linos E, Willett WC, Cho E, Frazier L. Adolescent diet in relation to breast cancer risk among premenopausal women. Cancer Epidemiol Biomarkers Prev. 2010;19(3):689-96.

30. Farvid MS, Cho E, Chen WY, Eliassen AH, Willett WC. Adolescent meat intake and breast cancer risk. Int J Cancer J Int Du Cancer. 2015;136(8):1909-20.

31. Dorgan JF, Liu L, Klifa C, Hylton N, Shepherd JA, Stanczyk FZ, Snetselaar LG, Van Horn L, Stevens VJ, Robson A, et al. Adolescent diet and subsequent serum hormones, breast density, and bone mineral density in young women: results of the Dietary Intervention Study in Children follow-up study. Cancer Epidemiol Biomarkers Prev. 2010;19(6):1545-56.

32. Mishra G, dos Santos SI, McNaughton S, Stephen A, Kuh D. Energy intake and dietary patterns in childhood and throughout adulthood and mammographic density: results from a British prospective cohort. Cancer Causes Control. 2011:22(2):227-35.

33. Tseng M, Olufade TO, Evers KA, Byrne C. Adolescent lifestyle factors and adult breast density in U.S. Chinese immigrant women. Nutr Cancer. 2011;63(3):342-9.

34. Sellers TA, Vachon CM, Pankratz VS, Janney CA, Fredericksen Z, Brandt KR, Huang Y, Couch FJ, Kushi LH, Cerhan JR. Association of childhood and adolescent anthropometric factors, physical activity, and diet with adult mammographic breast density. Am J Epidemiol. 2007;166(4):456-64

35. Bertrand KA, Burian RA, Eliassen AH, Willett WC, Tamimi RM. Adolescent intake of animal fat and red meat in relation to premenopausal mammographic density. Breast Cancer Res Treat. 2016:155(2):385-93.

36. Colditz GA, Hankinson SE. The Nurses' Health Study: lifestyle and health among women. Nat Rev Cancer. 2005:5(5):388-96.

37. Tworoger SS, Sluss P, Hankinson SE. Association between plasma prolactin concentrations and risk of breast cancer among predominately premenopausal women. Cancer Res. 2006;66(4):2476-82.

38. Bertrand KA, Rosner B, Eliassen AH, Hankinson SE, Rexrode KM, Willett W, Tamimi RM. Premenopausal plasma 25-hydroxyvitamin D, mammographic density, and risk of breast cancer. Breast Cancer Res Treat. 2015;149(2):479-87.

39. Farvid MS, Cho E, Chen WY, Eliassen AH, Willett WC. Dietary protein sources in early adulthood and breast cancer incidence: prospective cohort study. BMJ. 2014;348:93437.

40. Maruti SS, Feskanich D, Colditz GA, Frazier AL, Sampson LA, Michels KB, Hunter DJ, Spiegelman D, Willett WC. Adult recall of adolescent diet: reproducibility and comparison with maternal reporting. Am J Epidemiol. 2005:161(1):89-97.

41. Byng JW, Boyd NF, Little L, Lockwood G, Fishell E, Jong RA, Yaffe MJ. Symmetry of projection in the quantitative analysis of mammographic images. Eur J Cancer Prev. 1996;5(5):319-27.
42. Bertrand K, Eliassen AH, Hankinson S, Gierach G, Xu X, Rosner B, Ziegler R, Tamimi R. Urinary estrogens and estrogen metabolites and mammographic density in premenopausal women. Breast Cancer Res Treat. 2012;136(1):277-87.

43. Willett W, Stampfer MJ, Bain C, Lipnick R, Speizer FE, Rosner B, Cramer D, Hennekens $\mathrm{CH}$. Cigarette smoking, relative weight, and menopause. Am J Epidemiol. 1983;117(6):651-8.

44. Stampfer MJ, Willett WC, Colditz GA, Rosner B, Speizer FE, Hennekens CH. A prospective study of postmenopausal estrogen therapy and coronary heart disease. N Engl J Med. 1985;313(17):1044-9.

45. Zeger SL, Liang KY. Longitudinal data analysis for discrete and continuous outcomes. Biometrics. 1986:42(1):121-30.

46. Dong JY, He K, Wang P, Qin LQ. Dietary fiber intake and risk of breast cancer: a meta-analysis of prospective cohort studies. Am J Clin Nutr. 2011;94(3):900-5.

47. Aune D, Chan DSM, Greenwood DC, Vieira AR, Rosenblatt DAN, Vieira R, Norat T. Dietary fiber and breast cancer risk: a systematic review and meta-analysis of prospective studies. Ann Oncol. 2012;23(6):1394-402.

48. Maynard M, Gunnell D, Emmett P, Frankel S, Davey S. Fruit, vegetables, and antioxidants in childhood and risk of adult cancer: the Boyd Orr cohort. J Epidemiol Community Health. 2003:57(3):218-25.

49. Su X, Tamimi RM, Collins LC, Baer HJ, Cho E, Sampson L, Willett WC, Schnitt SJ, Connolly JL, Rosner BA, et al. Intake of fiber and nuts during adolescence and incidence of proliferative benign breast disease. Cancer Causes Control. 2010;21(7):1033-46.

50. Crowe FL, Key TJ, Allen NE, Appleby PN, Roddam A, Overvad K, Grønbæk H, Tjønneland A, Halkjær J, Dossus L, et al. The association between diet and serum concentrations of IGF-I, IGFBP-1, IGFBP-2, and IGFBP-3 in the European Prospective Investigation into Cancer and Nutrition. Cancer Epidemiol Biomark Prev. 2009;18(5):1333-40.

51. Endogenous Hormones and Breast Cancer Collaborative Group, Key TJ, Appleby PN, Reeves GK, Travis RC, Brinton LA, et al. Insulin-like growth factor 1 (IGF1), IGF binding protein 3 (IGFBP3), and breast cancer risk: pooled individual data analysis of 17 prospective studies. Lancet Oncol. 2010;11(6):530-42.

52. Izzo L, Meggiorini ML, Nofroni I, Pala A, De Felice C, Meloni P, Simari T, Izzo S, Pugliese F, Impara L, et al. Insulin-like growth factor-I (IGF-1), IGF-binding protein-3 (IGFBP-3) and mammographic features. G Chir. 2012;33(5):153-62.

53. Diorio C, Pollak M, Byrne C, Mâsse B, Hébert-Croteau N, Yaffe M, Coté G, Bérubé S, Morin C, Brisson J. Insulin-like growth factor-I, IGF-binding protein-3, and mammographic breast density. Cancer Epidemiol Biomark Prev. 2005;14(5):1065-73.

54. Cuzick J, Warwick J, Pinney E, Duffy SW, Cawthorn S, Howell A, Forbes JF, Warren RM. Tamoxifen-induced reduction in mammographic density and breast cancer risk reduction: a nested case-control study. J Natl Cancer Inst. 2011;103(9):744-52.

55. Yaghjyan L, Colditz GA, Rosner B, Tamimi RM. Mammographic breast density and subsequent risk of breast cancer in postmenopausal women according to the time since the mammogram. Cancer Epidemiol Biomarkers Prev. 2013;22(6):1110-7.

56. Frazier AL, Willett WC, Colditz GA. Reproducibility of recall of adolescent diet: Nurses' Health Study (United States). Cancer Causes Control. 1995;6(6):499-506

\section{Submit your next manuscript to BioMed Central and we will help you at every step:}

- We accept pre-submission inquiries

- Our selector tool helps you to find the most relevant journal

- We provide round the clock customer support

- Convenient online submission

- Thorough peer review

- Inclusion in PubMed and all major indexing services

- Maximum visibility for your research

Submit your manuscript at www.biomedcentral.com/submit 